\title{
$\therefore$ IJCRR \\ Section: Healthcare \\ Rp-Hplc Method for Simultaneous Estimation of Vildagliptin and Metformin in Bulk and Pharmaceutical Formulations
} ISI Impact Factor (2019-20): 1.628 IC Value (2019): 90.81 SJIF (2020) $=7.893$

(c) (i) (3)

Copyright@IJCRR

\author{
V. Nagalakshmi ${ }^{1}$, G. Srinivas Rao ${ }^{1}$, N. Gayathri Devi ${ }^{1}$, S. Mohan ${ }^{2}$ \\ 'Ch.S.D.St. Theresa's College for Women (A), Eluru, Andhra Pradesh, India; ${ }^{2 B a p a t l a ~ E n g i n e e r i n g ~ C o l l e g e, ~ B a p a t l a, ~ A n d h r a ~ P r a d e s h, ~ I n d i a . ~}$
}

\section{ABSTRACT}

Background: Combination therapy of vildagliptin and metformin provides a comprehensive effect on cardiovascular risk factors in the form of preventing hyperinsulinemia and reducing insulin resistance.

Objective: To develop a simple, fast, precise, accurate, sensitive RP-HPLC method for simultaneous estimation of metformin and vildagliptin in pure and tablet dosage forms.

Method: The mobile phase, a mixture of acetonitrile, methanol and water $(15: 60: 25 \mathrm{v} / \mathrm{v})$ pumped at a flow rate of $1.0 \mathrm{ml} / \mathrm{min}$ through the column $\left(\mathrm{C} 18 ; 5 \mu, 4.6 \times 250 \mathrm{~mm}\right.$, Hypersil) at $35^{\circ} \mathrm{C}$ temperature. The mobile phase was degassed before use under vacuum by filtration through a $0.2 \mu$ nylon membrane. Concentrations were measured at $278 \mathrm{~nm}$ by a UV detector at a sensitivity of $20 \mu \mathrm{l}$.

Results: The linearity lies between 1-5 $\mu \mathrm{g} / \mathrm{ml}$ for metformin and 1-5 $\mu \mathrm{g} / \mathrm{ml}$ for vildagliptin in the method. The correlation coefficient $\left(\mathrm{r}^{2}\right)$ was found to be 0.982 and 0.998 for Metformin and vildagliptin, the limit of detection and limit of quantification were found to be 0.617 and $1.87 \mu \mathrm{g} / \mathrm{ml}$ for metformin and 0.154 and $0.468 \mu \mathrm{g} / \mathrm{ml}$ for vildagliptin, respectively. The results of the analysis have been validated statistically by recovery studies as per International Conference on Harmonization guidelines.

Conclusion: The method showed good reproducibility and recovery with $\% R S D<2$. Hence, the method was found to be rapid, specific, precise, and accurate and can be successfully applied for the routine analysis of metformin and vildagliptin in the pure and combined dosage form.

Key Words: Vildagliptin, Metformin hydrochloride, Antidiabetic drugs, RP-HPLC method, Simultaneous Estimation, Method development and validation

\section{INTRODUCTION}

Chemically known as 3-[diaminomethylidene]-1, 1-dimethylguanidine $\mathrm{HCl}$, metformin $\mathrm{HCl}$ is an oral pharmaceutical product used to treat type 2 diabetes mellitus. Metformin is considered an antihyperglycemic drug because, without inducing hypoglycaemia, it reduces blood glucose concentrations in type II diabetes. Metformin is widely known as an insulin sensitizer that leads to a decrease in insulin resistance and a clinically important decrease in insulin levels from plasma fasting. Modest weight loss is another well-known advantage of this drug. For obese type II diabetes patients, Metformin is the medication of choice. ${ }^{1,2}$

Chemically, Vildagliptin is known as pyrrolidine-2-carbonitrile, (2S)-1-\{2-[(3-hydroxyadamantan-1-yl) amino] acetyl $\}$. Vildagliptin, previously known as LAF237, is a novel oral antidiabetic drug in the drug class of the new dipeptidyl peptidase-4 (DPP-4) inhibitor. Vildagliptin subsequently works by inhibiting glucagon-like peptide-1 (GLP-1) and gastric polypeptide inhibitor (GIP) inactivation by DPP-4., ${ }^{3,4}$

Literature review reveals that for estimation of metformin and vildagliptin in combination and individual dosage form $^{5-9}$ and validated with parameters, ${ }^{10-16}$ various analytical methods such as UV-Vis spectroscopy, HPLC and LCMS / MS methods are available. Without using any buffers, the procedure with new composition was developed in the estimation of these compounds using RP-HPLC methods and also the development and validation of a simple, precise, fast and specific method for the determination of metformin and vildagliptin in pure form and its pharmaceutical dosage form were considered of interest.

\section{Corresponding Author:}

V. Nagalakshmi, Ch.S.D. St. Theresa's College for Women (A), Eluru, Andhra Pradesh, India.

Email: cnlaxmi1@gmail.com

ISSN: 2231-2196 (Print)

ISSN: 0975-5241 (Online)

Received: 29.08 .2020

Revised: 02.11 .2020

Accepted: 18.12 .2020

Published: 12.04 .2021 


\section{MATERIALS AND METHODS}

\section{Chromatographic conditions}

Column: ODS $(4.6 \times 250 \mathrm{~mm}, 5 \mu \mathrm{m}$, Hypersil)

Mobile phase: ACN: Methanol: Water (15:60:25)

Flow rate: $1 \mathrm{ml} / \mathrm{min}$

Column temperature: $35^{\circ} \mathrm{C}$

The volume of injection: $20 \mu 1$

$\lambda \max : 278 \mathrm{~nm}$

\section{Degradation studies}

The forced degradation was carried under acidic, basic, oxidative conditions. Both the drugs were separately exposed to stress conditions. After exposing stress conditions, drugs were diluted to the standard concentration of Metformin $(30 \mu \mathrm{g} / \mathrm{ml} \& 160 \mu \mathrm{g} / \mathrm{ml})$ and Vildagliptin $(30 \mu \mathrm{g} / \mathrm{ml} \mathrm{\&} 160 \mu \mathrm{g} /$ $\mathrm{ml}$ ). Equal volume of both drugs were mixed and analyzed in the chromatographic conditions. The acid stress condition was carried out using $1 \mathrm{~N} \mathrm{HCl}$, when mixed with the drug solution and kept for 48hours and then injected into the chromatographic column, degradants evaluated using chromatograms. The alkali hydrolysis was carried out using $1 \mathrm{~N} \mathrm{NaOH}$, when mixed with the drug solution and kept for 48hours and then injected into the chromatographic column to evaluate the degradedness. Hydrogen peroxide is a strong oxidant when $3 \% \mathrm{H}_{2} \mathrm{O}_{2}$ was added to the $1000 \mu \mathrm{g} / \mathrm{ml}$ drug and kept for 48hours and injected into the chromatographic column to check the degradation.

\section{RESULTS}

\section{Validation by Method}

The method defined has been validated, including parameters such as suitability of the system, linearity, accuracy, precision, robustness, LOD and LOQ.

\section{System suitability}

Results of the system suitability study are summarized in the above table 1. Six consecutive injections of the standard solution showed uniform retention time, theoretical plate count, tailing factor and resolution for both the drugs which indicate a good system for analysis.

\section{Specificity}

The analytical peak was evaluated as per the methodology and observed the interference of blank, placebo with the analyte peak was there or not. Metformin and vildagliptin peaks were observed at their respective retention times of analyte peaks in figure 3 and 4 . When the blank solution was injected, no peak was found in figure 2 . The forced degradation study showed the method was highly specific; the chro- matographic peak does not interfere with any other impurities. This proves that excipients do not affect the analytical method. On the other hand, the blank peak did not overlap the drug peak. So the method is highly selective.

\section{Accuracy}

Validated the accuracy in this method, accurately quantify metformin and vildagliptin tablets content at 50\%, 100\%, $150 \%$ and performed assay in triplicate. The mean per cent recovery of metformin and vildagliptin at each spike level should be not less than $98 \%$ and not more than $102 \%$. Results of the accuracy study are presented in table 2 . The measured value was obtained by the recovery test. The spiked amount of both the drugs were compared against the recovery amount.

\section{Precision}

The precision of the test method by preparing six test preparations using the product blend by mixing the active ingredient with excipients as per the manufacturing formula was determined. Repeatability of Standard metformin and vildagliptin solution was injected six times and peak areas were measured and metformin \&vildagliptin per cent RSD was found to be $0.566 \& 1.903$. Results are given in table 3 .

\section{Linearity}

A linear relationship between peak areas versus concentrations was observed for metformin and vildagliptin in the range of $50 \%$ to $150 \%$ of normal concentration. The correlation coefficient was 0.982 for metformin and 0.988 for vildagliptin. This proves that the method is linear in the range of $50 \%$ to $150 \%$. Results are given in Table 4 .

\section{Robustness}

The results of the robustness of the present method had shown by changes in the flow rate and wavelength did not produce significant changes in analytical results which were presented in table 5. As the changes are not significant we can say that the method is robust.

\section{The Detection Limit}

LOD for Hydrochloride of metformin $=0.6177$

$\mathrm{LOD}=0.1544$ for vildagliptin

\section{Limit of Quantification}

LOQ for Hydrochloride of metformin $=1.8711$

$\mathrm{LOQ}=0.4688$ for vildagliptin

The LOD and LOQ values indicate that the method developed was sensitive, precise and reliable. 


\section{Studies of stability}

Comparative studies were performed on drugs called metformin and vildagliptin before and after degradation, and acid, base and oxidative degradation results were reported in Table 6.

\section{Research on Stress Degradation}

The properties of stress degradation were analysed using a validated chromatographic method for metformin and vildagliptin. Studies of forced degradation are listed in the table. Reports show that the validated approach effectively isolated and separately classified the degradation products. From the reports, it is very clear that drugs were responsive to acidic environments where there was less degradation.

\section{DISCUSSION}

The proposed method for the simultaneous determination of metformin and vildagliptin in pharmaceutical dosage form was found to be precise, selective, rapid and economical. ${ }^{5}$ The interaction study between the two drugs in the standard solution was carried out by comparing peaks of each drug individually with peaks obtained in drug mixture indicating that the analytes did not interact with each other and data were within the acceptance level of $\pm 2.0 \% .{ }^{1}$ The linearity for detector response was observed in the concentration range of 50 to $150 \%$ of test concentration and the correlation coefficient (r) for the calibration curve was found to be 1.0. Per cent recovery was found to be within the range of $98.0 \%$ to $102.0 \%$ indicating the accuracy of the method. ${ }^{6}$ The per cent RSD for the tablet analysis and recovery studied is less than 2 which is indicating a high degree of precision. ${ }^{5}$ The results of recovery studies were found to be linear in $50 \%$ to $150 \%$ of the final assay concentration range indicating linearity and range of the proposed method. The results of the robustness study indicate that the method is robust and is unaffected by small variations in the wavelength and flow rate trails. ${ }^{7}$ Hence, it can be concluded that the developed RP-HPLC method is accurate, precise, rapid and selective and can be employed successfully for the estimation of metformin and vildagliptin in bulk and pharmaceutical dosage forms. ${ }^{8}$ Degradation was not observed in metformin and vildagliptin stressed samples that were subjected to acid hydrolysis and oxidative conditions. However, degradation was observed under base hydrolysis. This indicates that the method is specific and stability-indicating. ${ }^{1}$

\section{CONCLUSION}

In pharmaceutical formulations, the author sheds light on the enhancement of HPLC methods for estimating metformin hydrochloride and vildagliptin. It is usually important to design methods in which a very large number of samples are to be analysed with appropriate precision and accuracy in a very short period. It is possible to obtain qualitative results via the HPLC process and can thus be used in analytical analysis. This is an effective technique that provides good results for validation parameters. This approach explicitly performs well on Metformin hydrochloride and Vildagliptin.

\section{ACKNOWLEDGMENT}

The authors thanks to the Department of Chemistry, Ch.S.D.St.Theresa's College for Women (A), Eluru for providing workspace and the authors are grateful to Icon Pharmaceutical Lab for providing instrumental support.

Conflict of Interest: The authors declare that no conflict of interest for this research. No funding support for this research

\section{REFERENCES}

1. Alaa SA, Soha F, Mohamad MM, Abo T. Simultaneous for the Estimation of Metformin and Empagliflozin in Pharmaceutical Dosage Form by HPLC Method. IOSR J Pharm Bio Sci 2019;14(1):75-80.

2. Thornberry NA Gallwitz B. Mechanism of action of inhibitors of dipeptidyl-peptidase-4 (DPP-4). Best Pract Res Clin Endocrinol Metab 2009;23(4):479-486.

3. Ahren B, Landin Olsson, Jansson M. Inhibition of dipeptidyl peptidase-4 reduces glycemia, sustains insulin levels, and reduces glucagon levels in type 2 diabetes. J Clin Endocrinol Metab 2004; 89(5):2078-2084.

4. Mentlein R, Gallwitz B,Schmidt. Dipeptidyl-peptidase IV hydrolyses gastric inhibitory polypeptide, glucagon-like peptide-1(7-36) amide, peptide histidine methionine and is responsible for their degradation in human serum. Eur J Biochem 1993;214(3):829-835.

5. Shirode1 AR, Maduskar PD, Deodhar MS, Kadam VJ. RPHPLC and HPTLC methods for simultaneous estimation of Metformin Hydrochloride and Vildagliptin from bulk and their marketed formulation: Development and Validation. Br J Pharm Sci 2014;4(20):2370-2386.

6. Abu DW, Hamad M, Mallah E, Abu DA, Awad R, Zakaria Z, et.al. Method Development and Validation of Vildagliptin and Metformin $\mathrm{HCl}$ in pharmaceutical dosage form by Reverse phase-High performance liquid chromatography (RP-HPLC). Int J Pharm Sci Res 2018; 9(7):2965-2972.

7. Subhakar N, Krishna Reddy V, Ravindranadh Reddy T. Development and Validation of RP-HPLC method for simultaneous determination of Vildagliptin and Metformin in bulk and formulation dosage. Int Res J Pharm Appl Sci 2012;2(3):44-50.

8. Srinivas Ch, AnilkumarCh, Nagaraju B, Nagajyothi J. Method development and Validation by RP-HPLC for the simultaneous estimation of Metformin and Vildagliptin in pharmaceutical dosage form. Eur J Pharma Med Res 2017;4(6):01-16.

9. Priyanka DP, Saurabh D, Pandya S. The aim of this review to focus on a comprehensive update of different analytical methods for determination of oral anti-diabetic drugs for the treatment of type 2 diabetes mellitus (T2DM). World J Pharm Sci 2018;6(1):29-39. 
10. International Conference on Harmonization (ICH); Q2 (R1), Validation of analytical procedures: Text and methodology, Geneva, Switzerland, (2005).

11. United state Pharmacopoeia, USP 32, NF27, Page No. 2906, 2007.

12. Mohammad A, Azim Md, Elkady EF, Fouad A. Development and validation of a reversed phase column liquid chromatographic method for simultaneous determination of two novel gliptins in their binary mixtures with Metformin. Eur J Chem 2012;3(2):152-155.

13. Shaikh KA, Patil SD, Devkhile AB. Development and validation of a reversed-phase HPLC method for simultaneous estimation

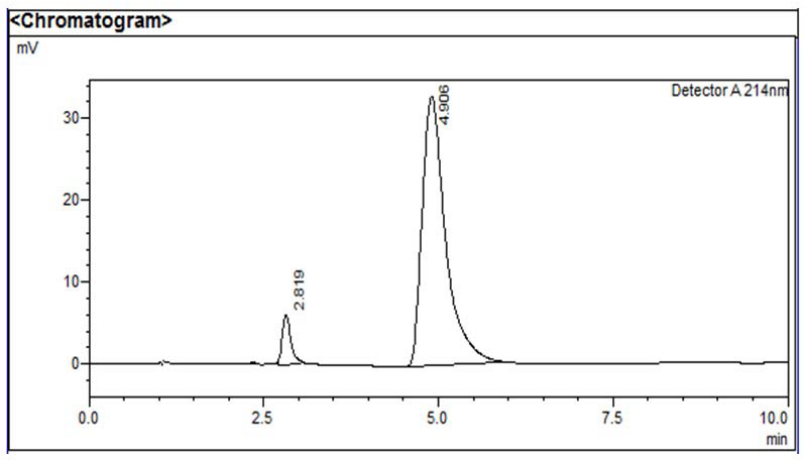

Figure 1: Chromatogram for the optimized method.

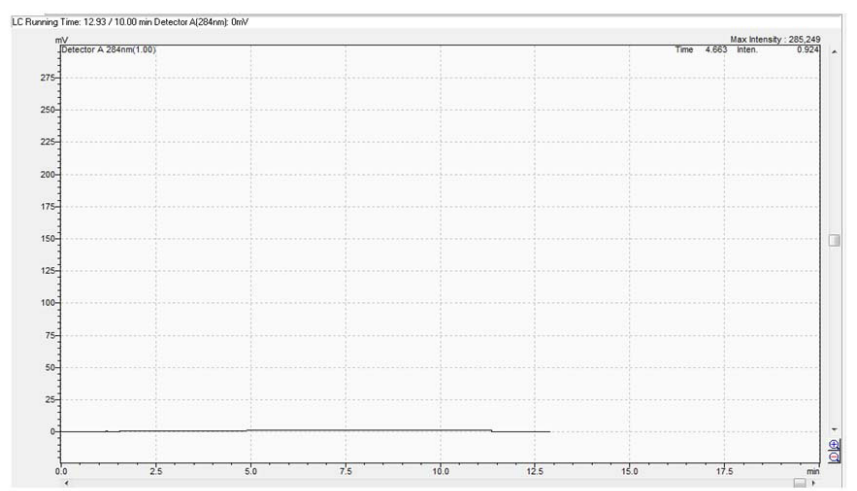

Figure 2: Typical chromatogram of the blank solution.

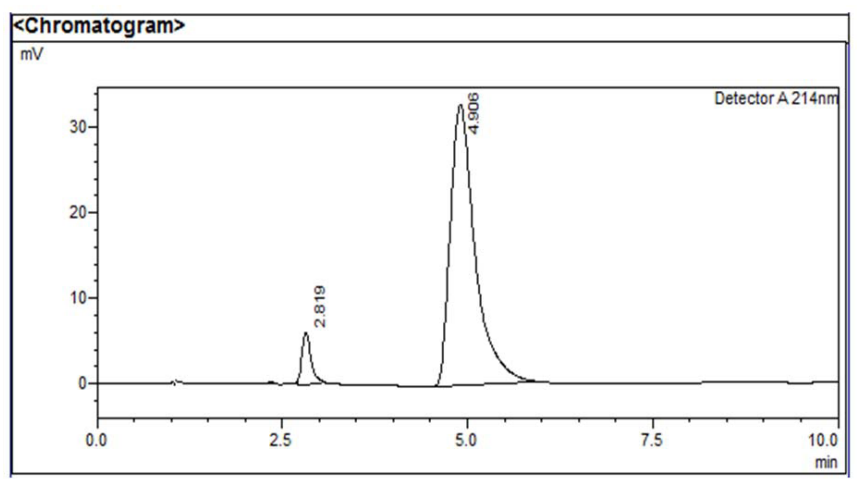

Figure 3: Typical chromatogram of the standard solution. of ambroxol hydrochloride and azithromycin in tablet dosage form. J Pharm Biomed Anal 2008;48(5):1481-1484.

14. Santhosha B, Ravindranath A, Sundari Ch. Validated method for the simultaneous estimation of Metformin Hydrochloride and VIDA by RP-HPLC in bulk and the pharmaceutical dosage form. Int Res J Pharm App Sci 2012;2(3):22-28.

15. De AK, Ashokkumar B, Pal B. Development and Validation of Same RP-HPLC Method for Separate Estimation of Theophylline and Doxofylline in Tablet Dosage Forms. J Curr Pharm Res 2012;9(1):55-58.

16. Devika GS, Sudhakar M. RP HPLC method for simultaneous estimation of metolazone and ramipril in oral solid dosage form. Int J Pharm Bio Sci 2012;3(4):193-200.

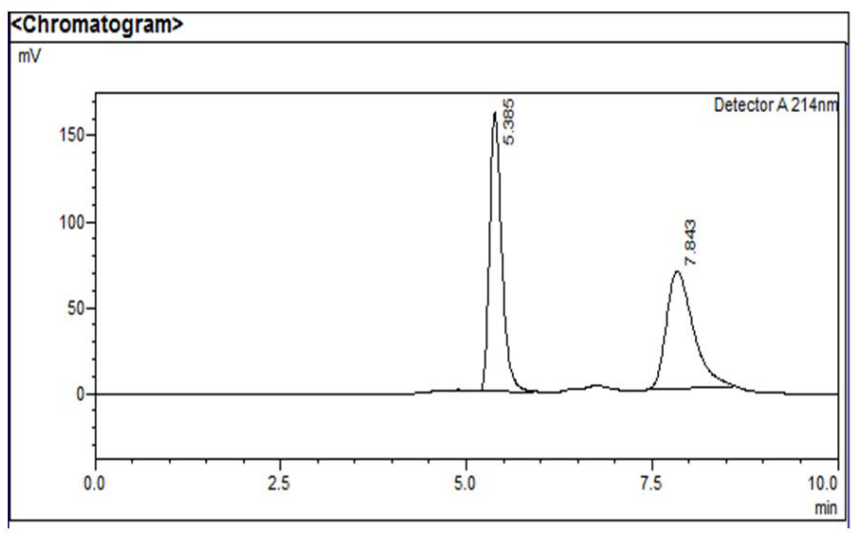

Figure 4: Typical chromatogram of the sample solution.

Table 1: System suitability for Metformin and Vildagliptin

\begin{tabular}{|c|c|c|c|c|c|}
\hline Sample & Injection & $\begin{array}{c}\text { RT } \\
\text { (Min) }\end{array}$ & $\begin{array}{l}\text { Peak } \\
\text { Area }\end{array}$ & $\begin{array}{l}\text { USP } \\
\text { Plate } \\
\text { count }\end{array}$ & $\begin{array}{c}\text { USP } \\
\text { Tailing }\end{array}$ \\
\hline \multirow[t]{8}{*}{ Metformin } & 1 & $4 \cdot 960$ & 76492 & 7242 & 1.653 \\
\hline & 2 & 4.906 & 76816 & 7665 & 1.709 \\
\hline & 3 & 4.856 & 78590 & 7876 & 1.732 \\
\hline & 4 & 4.823 & 76262 & 8260 & 1.760 \\
\hline & 5 & $4 \cdot 776$ & 77416 & 8205 & 1.773 \\
\hline & Mean & & 77115.2 & & \\
\hline & SD & & 931.579 & & \\
\hline & \% RSD & & 1.208 & & \\
\hline \multirow[t]{8}{*}{ Vildagliptin } & 1 & 2.823 & 49597 & 16529 & - \\
\hline & 2 & 2.819 & 48742 & 17463 & 1.420 \\
\hline & 3 & 2.834 & 47396 & 17549 & - \\
\hline & 4 & 2.831 & 48223 & 18867 & 1.193 \\
\hline & 5 & 2.838 & 47359 & 17408 & 1.443 \\
\hline & Mean & & 48263.4 & & \\
\hline & SD & & $945 \cdot 978$ & & \\
\hline & $\%$ RSD & & 1.96 & & \\
\hline
\end{tabular}


Table 2: Accuracy data for Metformin and Vildagliptin

\begin{tabular}{|c|c|c|c|c|c|c|c|}
\hline Sample & $\begin{array}{l}\text { Accuracy } \\
\text { level }\end{array}$ & $\begin{array}{c}\text { Sample } \\
\text { name }\end{array}$ & Sample weight & $\begin{array}{l}\mu \mathrm{gg} / \mathrm{ml} \\
\text { added }\end{array}$ & $\begin{array}{l}\mu \mathrm{g} / \mathrm{ml} \\
\text { found }\end{array}$ & $\%$ recovery & \% Mean \\
\hline \multirow{9}{*}{ Metformin } & \multirow{3}{*}{$50 \%$} & 1 & 50 & 50 & 48.674 & $96.34 \%$ & \multirow{3}{*}{$99 \cdot 34 \%$} \\
\hline & & 2 & 50 & 50 & 49.232 & $99 \cdot 36 \%$ & \\
\hline & & 3 & 50 & 50 & 51.168 & $102.33 \%$ & \\
\hline & \multirow{3}{*}{$100 \%$} & 1 & 100 & 100 & 101.171 & $101.17 \%$ & \multirow{3}{*}{$101.33 \%$} \\
\hline & & 2 & 100 & 100 & 100.863 & $100.86 \%$ & \\
\hline & & 3 & 100 & 100 & 101.96 & $101.96 \%$ & \\
\hline & \multirow{3}{*}{$150 \%$} & 1 & 150 & 150 & 146.623 & $97 \cdot 748 \%$ & \multirow{3}{*}{$100.06 \%$} \\
\hline & & 2 & 150 & 150 & 152.912 & $101.94 \%$ & \\
\hline & & 3 & 150 & 150 & 150.753 & $100.50 \%$ & \\
\hline \multirow{9}{*}{ Vildagliptin } & \multirow{3}{*}{$50 \%$} & 1 & 50 & 50 & 49.21 & $98.42 \%$ & \multirow{3}{*}{$50 \%$} \\
\hline & & 2 & 50 & 50 & 50.479 & $100.95 \%$ & \\
\hline & & 3 & 50 & 50 & 48.302 & $96.64 \%$ & \\
\hline & \multirow{3}{*}{$100 \%$} & 1 & 100 & 100 & 107.78 & $107.78 \%$ & \multirow{3}{*}{$100 \%$} \\
\hline & & 2 & 100 & 100 & 95.98 & $95.98 \%$ & \\
\hline & & 3 & 100 & 100 & 100.138 & $100.138 \%$ & \\
\hline & \multirow{3}{*}{$150 \%$} & 1 & 150 & 150 & $145 \cdot 71$ & $97.14 \%$ & \multirow{3}{*}{$150 \%$} \\
\hline & & 2 & 150 & 150 & 150.674 & $100.44 \%$ & \\
\hline & & 3 & 150 & 150 & 153.711 & $102.474 \%$ & \\
\hline
\end{tabular}

Table 3: Precision data for Metformin and Vildagliptin

\begin{tabular}{|c|c|c|c|c|c|}
\hline Sample & Injection No & $\mathbf{R}_{\mathrm{t}}$ (mins) & Area & Tailing Factor & Plate count \\
\hline \multirow{9}{*}{ Metformin } & 1 & $4 \cdot 776$ & 774164 & 1.773 & 8250 \\
\hline & 2 & 4.823 & 762622 & 1.760 & 8260 \\
\hline & 3 & 4.856 & 765900 & 1.732 & 7876 \\
\hline & 4 & 4.906 & 767672 & 1.680 & 7642 \\
\hline & 5 & 4.960 & 764921 & 1.653 & 7242 \\
\hline & 6 & 4.783 & 771735 & 1.685 & 7158 \\
\hline & Mean & & 767835.66 & & \\
\hline & Std. Dev. & & 4352.098 & & \\
\hline & \%RSD & & 0.566 & & \\
\hline \multirow{9}{*}{ Vildagliptin } & 1 & 2.838 & 47359 & 1.443 & 17408 \\
\hline & 2 & 2.831 & 47223 & 1.193 & 18867 \\
\hline & 3 & 2.835 & 45396 & - & 17549 \\
\hline & 4 & 2.819 & 47582 & - & 16856 \\
\hline & 5 & 2.823 & 47597 & - & 16529 \\
\hline & 6 & 2.890 & 47872 & 1.433 & 18695 \\
\hline & Mean & & 47171.5 & & \\
\hline & Std. Dev. & & 897.827 & & \\
\hline & \% RSD & & 1.903 & & \\
\hline
\end{tabular}


Table 4: Calibration curve data for Metformin and Vildagliptin

\begin{tabular}{lccc} 
Sample & Peak Area & Correlation co-efficient \\
& 1 & 472645 & \\
Metformin & 2 & 487296 & 0.982 \\
& 3 & 494104 & \\
& 4 & 501819 & \\
& 5 & 512770 & \\
& 1 & 124157 & 0.998 \\
Vildagliptin & 2 & 142770 & \\
& 3 & 163685 & \\
& 4 & 185745 & 203685 \\
\hline
\end{tabular}

Table 5: Robustness data for Metformin and Vildagliptin

\begin{tabular}{|c|c|c|c|c|c|}
\hline Sample & Parameter & $\mathbf{R}_{t}(\min )$ & Peak Area & Tailing factor & $\begin{array}{c}\text { Theoretical } \\
\text { plates }\end{array}$ \\
\hline \multirow{5}{*}{ Metformin } & Limits & $>2 \min$ & & NMT 2.0 & NLT 2000 \\
\hline & Flow rate $(0.8 \mathrm{~mL} / \mathrm{min})$ & 7.544 & 980324 & 1.615 & 6434 \\
\hline & Flow rate $(0.6 \mathrm{~mL} / \mathrm{min})$ & 10.347 & 1289313 & 1.337 & 4588 \\
\hline & Wave length (219nm) & 4.792 & 748602 & 1.664 & 8170 \\
\hline & Wave length (209nm) & 1.685 & 831735 & 1.685 & 7158 \\
\hline \multirow{5}{*}{ Vildagliptin } & Limits & $>2 \min$ & & NMT 2.0 & NLT 2000 \\
\hline & Flow rate $(0.8 \mathrm{~mL} / \mathrm{min})$ & 7.544 & 980324 & 1.615 & 6434 \\
\hline & Flow rate $(0.6 \mathrm{~mL} / \mathrm{min})$ & 10.347 & 1289313 & 1.337 & 4588 \\
\hline & Wave length (219nm) & 4.792 & 748602 & 1.664 & 8170 \\
\hline & Wave length (209nm) & 1.685 & 831735 & 1.685 & 7158 \\
\hline
\end{tabular}

Table 6: Stability data for Metformin and Vildagliptin

\begin{tabular}{|c|c|c|c|c|c|}
\hline Sample & Degradation studies & $\begin{array}{c}\mathbf{R t} \\
(\mathrm{min})\end{array}$ & Area & Theoretical plates & Tailing factor \\
\hline \multirow{6}{*}{ Metformin } & Acid Degradation-30 $\mu \mathrm{g} / \mathrm{ml}$ & 4.740 & 770848 & 842 & 1.635 \\
\hline & Acid Degradation-16o $\mu \mathrm{g} / \mathrm{ml}$ & 5.337 & 235206 & 346 & 1.216 \\
\hline & Alkali Degradation - $30 \mu \mathrm{g} / \mathrm{ml}$ & 2.331 & 278667 & 890 & 1.297 \\
\hline & Alkali Degradation $-160 \mu \mathrm{g} / \mathrm{ml}$ & 2.403 & 424477 & 1466 & - \\
\hline & Oxidation $-30 \mu \mathrm{g} / \mathrm{ml}$ & 4.770 & 30339 & 1413 & 2.462 \\
\hline & Oxidation $-160 \mu \mathrm{g} / \mathrm{ml}$ & 4.806 & 68162 & 1309 & 2.467 \\
\hline \multirow{6}{*}{ Vildagliptin } & Acid Degradation-30 $\mu \mathrm{g} / \mathrm{ml}$ & 2.035 & 37277 & 306 & 0.883 \\
\hline & Acid Degradation-16o $\mu \mathrm{g} / \mathrm{ml}$ & 1.972 & 31169 & 237 & 1.231 \\
\hline & Alkali Degradation-зopg/ml & 2.391 & 266639 & 1980 & 1.838 \\
\hline & Alkali Degradation-16oug/ml & 2.352 & 445057 & 1459 & - \\
\hline & Oxidation $-30 \mu \mathrm{g} / \mathrm{ml}$ & 2.889 & 224263 & 1171 & - \\
\hline & Oxidation $-160 \mu \mathrm{g} / \mathrm{ml}$ & 3.712 & 163058 & 625 & 2.443 \\
\hline
\end{tabular}

